\title{
Construcciones sociales y actitudes hacia el enamoramiento en la adolescencia
}

\section{Social constructions and attitudes towards falling in love in adolescence age}

\begin{tabular}{c} 
Paula Andrea Rodríguez Rincón ${ }^{1}$ \\
\hline Lina Nayarid Triviño Cervera ${ }^{2}$ \\
\hline Jaime Duván Reyes Roncancio ${ }^{3}$ \\
\hline Edier Hernán Bustos Velasco $0^{4}$ \\
\hline Universidad Distrital \\
Francisco José de Caldas
\end{tabular}

$\overline{\overline{1} \quad \text { Docente de básica y media en institución privada }}$ de Bogotá. Licenciada en biología de la Universidad Distrital Francisco José de Caldas, 2019. pauarodriguezr@correo. udistrital.edu.co https://orcid.org/0000-0003-4318-544X $2 \quad$ Docente de básica y media en institución privada de Bogotá. Licenciada en biología de la Universidad Distrital Francisco José de Caldas, 2019. lintrivinoc@correo.udistrital.edu.co https://orcid.org/0000-0001-7685-801X

3 Docente Universidad Distrital Francisco José de Caldas. Licenciado en Física, Universidad Distrital Francisco José de Caldas, 1991. Magister en Docencia de la Física, Universidad Pedagógica Nacional, 1999. Doctor en Educación, Universidad Distrital Francisco José de Caldas.2014.jdreyesr@udistrital.edu.co.CvLAChttps://scienti. minciencias.gov.co/cvlac/visualizador/generarCurriculoCv. https://orcid.org/0000-0002-9229-1196

$4 \quad$ Docente Universidad Distrital Francisco José de Caldas. Licenciado en Matemáticas y Física de la Universidad de Cundinamarca. 2000. Magister en Educación. Universidad Pedagógica Nacional. 2004. Doctor en Educación, énfasis Educación en Ciencias. Universidad Distrital Francisco José de Caldas, 2017. Candidato a doctor en Geografía, Universidad Nacional de la Plata, celular 3102056342 ehbustosv@udistrital.edu.co.

CVLAC http://scienti.colcien-cias.gov.co:8081/cvlac/visualizador/generarCurriculoCv. do?cod rh $=0000714577$ https://orcid.org/0000-0003-0072-8598

\section{RESUMEN}

En el presente artículo, resultado de investigación, se identifican las actitudes frente al enamoramiento de un grupo de estudiantes de octavo grado de básica secundaria en un colegio de la ciudad de Bogotá. La metodología de corte cualitativo se desarrolló mediante vivencias de aprendizaje (hormonas y amor) que incluyeron narraciones, representaciones y declaraciones basadas en experiencias propias o hipotéticas sobre relaciones amorosas. El análisis de los resultados evidencia características distintivas del enamoramiento asociado a propiedades de las interacciones entre los adolescentes que usualmente se reconocen como tóxica stalkear, parla y otros, destacándose narrativas asociadas a sufrimiento y violencia, el amor el 
poder y la realidad, que hacen parte de las ideas sobre amistad y noviazgo

\section{PALABRAS CLAVE:}

Enamoramiento, relación con otros, adolescentes, actitudes, experiencias.

\section{ABSTRACT}

This article, as a research result, identifies the attitudes towards falling in love of a group of 8th grade students in a school in the city of Bogotá. The qualitative methodology was developed through learning experiences (hormones and love) that included narratives, representations and statements based on their own or hypothetical experiences about love relationships. The analysis of the results evidences distinctive characteristics of infatuation associated with properties of interactions between adolescents that are usually recognized as toxic - stalking, chatting and others, highlighting narratives associated with suffering and violence, love, power and reality, that are part of the ideas about friendship and courtship

\section{KEYWORDS:}

Falling in love, relationship with others, adolescents, attitudes, experiences.

\section{MARCO TEÓRICO}

En la adolescencia las relaciones románticas son importantes porque desempeñan el enfrentamiento de retos, la formación de identidad, el desarrollo de habilidades de interacción con iguales y su papel como factor de adaptación a la adultez; las relaciones románticas en esta etapa juegan un papel muy importante para el desarrollo de las habilidades de cortejo, intimidad y autonomía. (Caycedo, et. al., 2007). Como consecuencia de esto los adolescentes entablan relaciones de carácter significativo con personas que no pertenecen al núcleo familiar. Uno de los principales intereses es llegar a establecer y a mantener relaciones románicas de manera exitosa (Penagos, et. al., 2006).

La adolescencia es tiempo y espacio de aprendizajes, de ensayar roles de pareja y experimentar nuevas sensaciones, según Trujillo \& Barrera (2002), las relaciones románticas en la adolescencia se caracterizan porque involucran a dos individuos que reconocen algún tipo de vínculo entre sí, son voluntarias, existe algún tipo de atracción basada en la apariencia física, características de personalidad, la compatibilidad de intereses o habilidades, implican manifestaciones de compañerismo, intimidad, protección y apoyo. En el mismo sentido Penagos, et. al., (2006) sugieren que, uno de los principales intereses es el llegar a establecer y a mantener relaciones de tipo romántico de manera exitosa, se constituyen como base para, en etapas posteriores de la vida proporcionando elementos como afecto y seguridad

El amor es el componente más importante de las relaciones románticas, considerado un elemento de construcción social (Narváez, et. al., 2016). El amor desde esta perspectiva vendría a ser lo que técnicamente llamamos un vínculo afectivo positivo que se establece entre dos personas en la que se dan varios elementos clave: reciprocidad, apertura emocional, una inversión de tiempo y recursos personales, una intimidad compartida y un compromiso público. Con relación Sánchez (2019) argumenta que el enamoramiento supone el deseo y la atracción, este deseo es una pulsión que puede incluso vivirse con la confusión de no saber cómo satisfacerlo y con quien, y la atracción se refiere a personas concretas que son objeto del deseo, porque se perciben como más eróticas. 
En efecto el enamoramiento provoca un aumento del deseo respecto a la atracción sexual y afectiva que la persona vive "conmocionada", "exultante", entregada a una relación de ser correspondida, conduce a la unión sexual, emocional y vital (Sánchez., 2019). Por consiguiente, entendiendo la fenomenología del enamoramiento que incide como afirma Sánchez (2019), en aspectos fisiológicos por la producción de algunas sustancias como la dopamina y su derivado la norepinefrina, así como la serotonina y la oxitocina, provocando en la persona que se enamora un sentimiento de que se juega muchísimo debido a que estas sustancias aumentan la capacidad de atención, concentración, motivación, aceleración del pulso, sensación de opresión o estallido del pecho, ganas de llorar o cantar, hipertensión muscular, tendencia a la hiperactividad, temblores y dificultad para controlar las emociones y las respuestas fisiológicos".

Para finalizar, cabe aclarar que algunos adolescentes deciden tener relaciones sexuales porque están enamorados. La mayoría de los adolescentes no lo hacen. Aunque los adolescentes pueden besarse, abrazarse y tenerse de las manos, la realidad es que la mayoría de los chicos/as que están en cursos de bachillerato no tiene relaciones sexuales (Alfonso \& Figueroa, 2017)

\section{Metodología.}

Este trabajo se enmarca en la investigación cualitativa, definida por Denzin y Lincoln (1994), como una actividad situada que localiza al observador en el mundo, por medio de un conjunto de prácticas materiales interpretativas a través de las cuales buscamos la comprensión del mundo social. Bajo la premisa de la interpretación de los fenómenos sociales, recabamos las actitudes que presentan los estudiantes frente a la sexualidad y cuidado del cuerpo en el escenario del enamoramiento.
Para develar las actitudes de los estudiantes, se implementó una secuencia de vivencias. Cada una de estas, permitió tener en cuenta la experiencia de los estudiantes, potencializando habilidades como la participación, el diálogo y la reflexión (Torres, et_al__ 2017)

Se implementaron seis vivencias en un grupo de 40 estudiantes de octavo grado del Colegio Cooperativo Nuevo Muzu, Bogotá - Colombia. Estas incluían videos, canciones, cuestionarios gamificados, expresión verbal o escrita. Relacionaban sus experiencias sobre el proceso que han experimentado en las interrelaciones con otro cuando se enamora

Como herramienta de clasificación y organización de la información obtenida, se utilizó el software para análisis cualitativo MAXQDA $\square$, en el cual, partiendo de las categorías exploradas (fig. 1) teóricamente en el marco referencial, de la investigación macro, se clasificaron las producciones de los estudiantes conforme a estas. Conviene mencionar aquí elementos básicos de esta categorías que permiten identificar los hallazgos, en primer lugar la idea de Prácticas sexuales (experiencias) como reflejo de la estructura entre lo subjetivo y lo adquirido socialmente. En segundo lugar, la percepción de su imagen corporal comprendida como la autopercepción del cuerpo, lo que genera una representación mental del mismo. 
Fig. 1 Categorías en relación con el enamoramiento

\begin{tabular}{|c|c|c|c|}
\hline \multirow[b]{2}{*}{ LA AUTOIMACEN } & \multirow{5}{*}{$\begin{array}{l}\text { ACTITUDES HACIA EL } \\
\text { ENAMORAMIENTO }\end{array}$} & \multirow[b]{2}{*}{ SEXUALIDAD } & Enamoramiento \\
\hline & & & Interacción Con Otrxs \\
\hline LO SOCIALYY & & \multirow{3}{*}{$\begin{array}{l}\text { CUIDADO DEL } \\
\text { CUERPO }\end{array}$} & Prácticas Sexuales \\
\hline CULTURAL & & & Imonen \\
\hline LAS EXPERIENCIAS & & & Higiene \\
\hline
\end{tabular}

Fuente: Creación propia

Ahora bien, en cuanto a la higiene corporal se comprende aquí como el conjunto de conocimientos y técnicas que deben aplicar las personas para el control de los factores que ejercen efectos nocivos sobre su salud. Por último, la importancia de la interrelación con el otro (social y cultural), desde la expresión de la sexualidad estrechamente vinculada al entorno socio-cultural de los seres humanos.
Con todo, en el entendido de asumir la adolescencia como una etapa de la vida personal y social, inscrita en una serie de sucesos que marcan la transición entre la niñez y la adultez, en este artículo se exponen los productos más vinculados con la subcategoría de enamoramiento, que recaen en la vivencia titulada "En tiempos revueltos, ¿es posible amar?"

Fig_ 2. Proceso metodológico

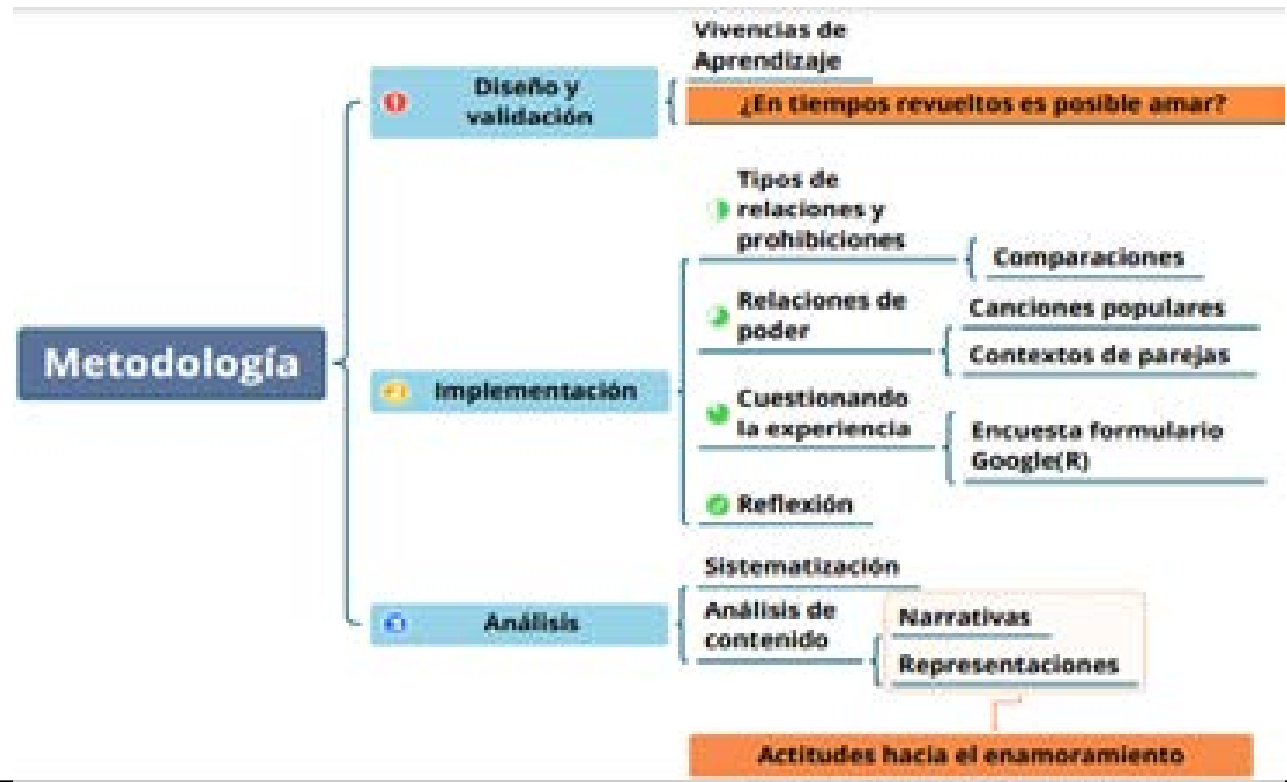

Fuente: Creación propia 
En esta vivencia, los estudiantes trabajaron en grupo estableciendo una tabla de comparación entre los tipos de relaciones y sus prohibiciones. Posteriormente, se expusieron diferentes situaciones de canciones populares que relatan relaciones de poder y contextos de parejas en este tipo de relación, seguido a esto se les cuestionó haciendo uso de un formulario de Google.

Los cuestionarios contemplados dentro de las vivencias tenían, preguntas abiertas y mixtas que les permitían expresar sus ideas, de manera más exhaustiva o tomando una opción. (Abarca,et. al., 2013). Diseñados, usando herramientas virtuales, las cuales permiten, una relación más cercana e interactiva de los cuestionarios. (Eisele-Dyrli, 2011) y (Calvillo y Martín 2017)

Las producciones de los estudiantes involucraron también composiciones tipo avatar, en las que contemplaron asociaciones entre tipos de relaciones, conocimientos científicos $y$ en algunos casos experiencias personales. Las imágenes construidas por los estudiantes según, Bateson (1998) y Serna (2008), permiten manifestar pensamientos, sentimientos, ideas, conocimientos, y a su vez dan cuenta del carácter del contexto social en el cual se crean y del que son completamente dependientes. Así, todo lo que se representa a través de la imagen tiene un origen en la realidad y en el contexto del sujeto que las produce.

Se utilizaron las siguientes fuentes de información en la vivencia:

a. La historia de Lorena. Técnicasgrupales-para-el-trabajo-en-sexualidad-conadolescentes-y-jovenes. (CEIP, 2005)

b. video: In a heart beat. https://youtu. be/2REkk9SCRno

c. video: canción amor tóxico. https://drive.google.com/drive/u/0/
folders/1XTOUFXkXzUATeoyEYKi_qbl5_

B6kys7-

\section{ANÁLISIS Y DISCUSIÓN}

En esta sección se presenta el análisis y resultados en relación con la categoría enamoramiento, considerando la participación de los estudiantes en la vivencia de aprendizaje $y$, en los casos que aplica, algunos referentes conceptuales que entran en la discusión teórica en relación con لos hallazgos.

\section{DEFINIENDO ELENAMORAMIENTO}

Respecto a las definiciones que los estudiantes dieron sobre el enamoramiento se encuentra en primer lugar, una perspectiva asociada a sus propias vivencias. Esto se observa en las declaraciones espontáneas que se daban en la clase. Se encuentra que en concordancia por lo descrito por Alberoni (1997), quien define al enamoramiento como una atracción repentina, un fuerte deseo de estar con la otra persona, un "flechazo", los estudiantes destacan que:

El enamoramiento es cuando uno empieza a sentir atracción por otra persona y tiene un sentimiento de amor (E01-M, 13 años)

Enamorarse es querer y amar a otros (E02- M, 15 años)

Estar enamorado me hace sentir mariposas en elestómago (E03-H,12 años)

Pensar en esa persona especial todo el día (E04-M, 13años)

Estar enamorado es feo porque te pueden engañar (E05- $H$, 15 años)

Estar enamorado te hace compartir mucho tiempo con esa persona (E06-H, 14 años)

Esto también se relaciona con la tendencia innata de exploración y desarrollo de los deseos y de amar a otros (Alberoni, 2008). 
Cabe resaltar que, en estudios adelantados en un grupo de jóvenes con el mismo rango de edades, se dilucida que entre los géneros existen pocas diferencias sobre las formas de concebir el amor, las jóvenes son más dadas a una entrega de sentimientos y el desamor, en cuanto a los jóvenes destacan lo placentero y tienen gran temor al rechazo. (López, Escalante, Keb, Canto, y Chan, 2011).

\section{REQUISITOS PARA ENAMORARSE}

En el siguiente apartado los estudiantes relacionaron a través de una representación gráfica (avatar), las características ideales (biológicas, emocionales, sociales), que ellos consideran fundamentales en el momento de enamorarse, surge la pregunta ¿Qué se necesita para enamorarse siendo adolescente? Cabe aclarar que previamente a la actividad estos recibieron información sobre ¿cómo actúan las hormonas en el proceso de enamoramiento y su mecanismo de acción? Posteriormente los estudiantes procedieron a representar sus avatares, adicionándoles poderes de base, relacionados con las hormonas. Cada uno le colocó el porcentaje de poder a las hormonas que consideró apropiado para el personaje.

Lo más destacable de cada uno de estos avatares, no son los poderes de base, sino los superpoderes que hacen especial al personaje. Se encontraron varias coincidencias entre los superpoderes. Esto nos llevó a organizar y tipificar en grupos de categorías : a. Tóxico Stalkeo, b. parla y, c. otros poderes

Importante destacar aquí que, contrariamente a lo que popularmente se cree, el interés principal de los jóvenes en sus primeras relaciones románticas no es satisfacer necesidades sexuales, sino encontrar ¿quiénes son ?, ¿qué tan atractivos resultan para el otro ?, aprender a interactuar en una relación de pareja y ganar estatus en su grupo de pares (Brown, 1999).

\section{Grupo categorial Tóxico-Stalkeo}

Fig 3 La_categoría Tóxico-Stalkeo súper poder en el enamoramiento
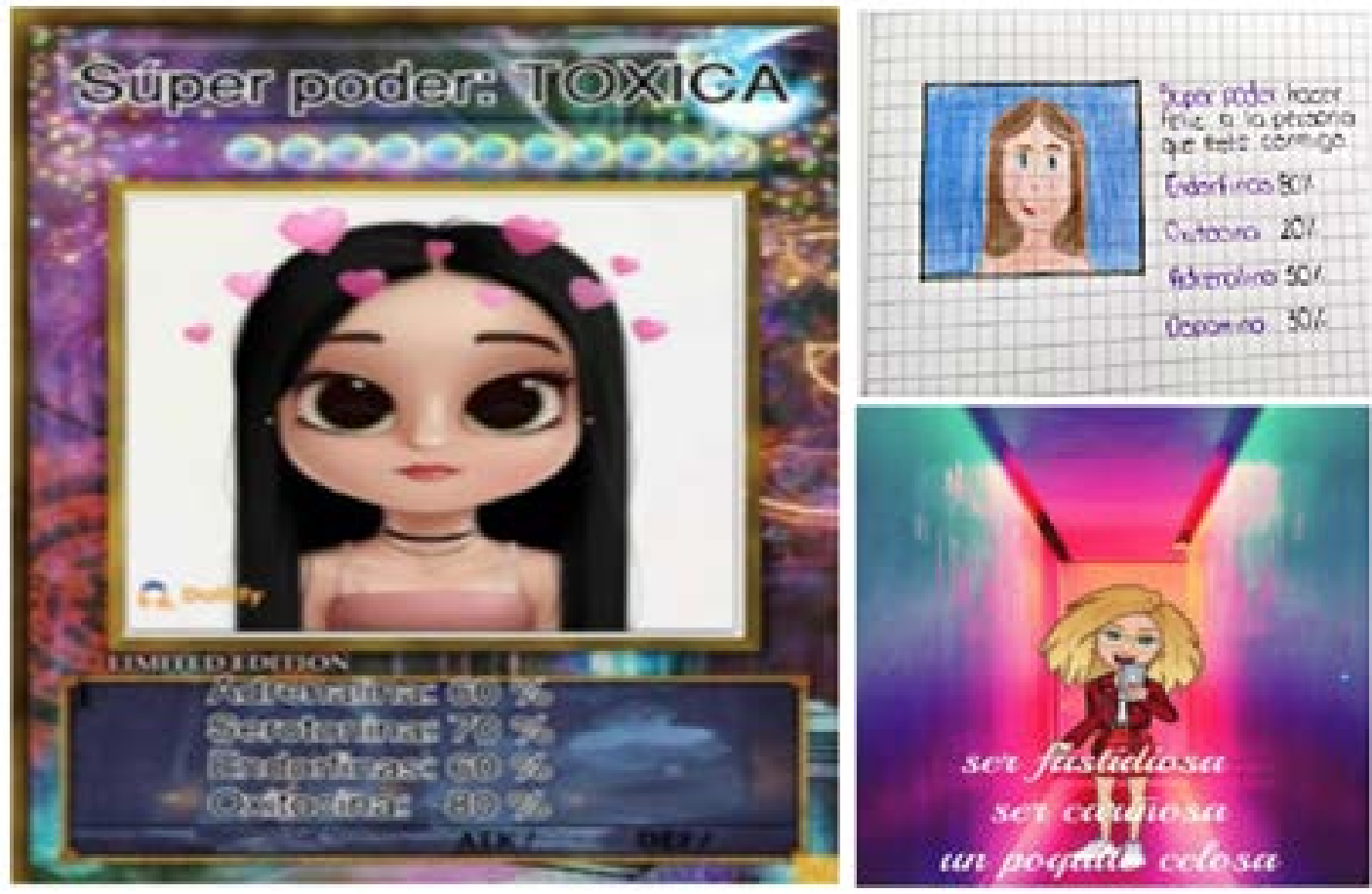

Fuente: Construcción estudiante F01-M,E02-M,F04-M 

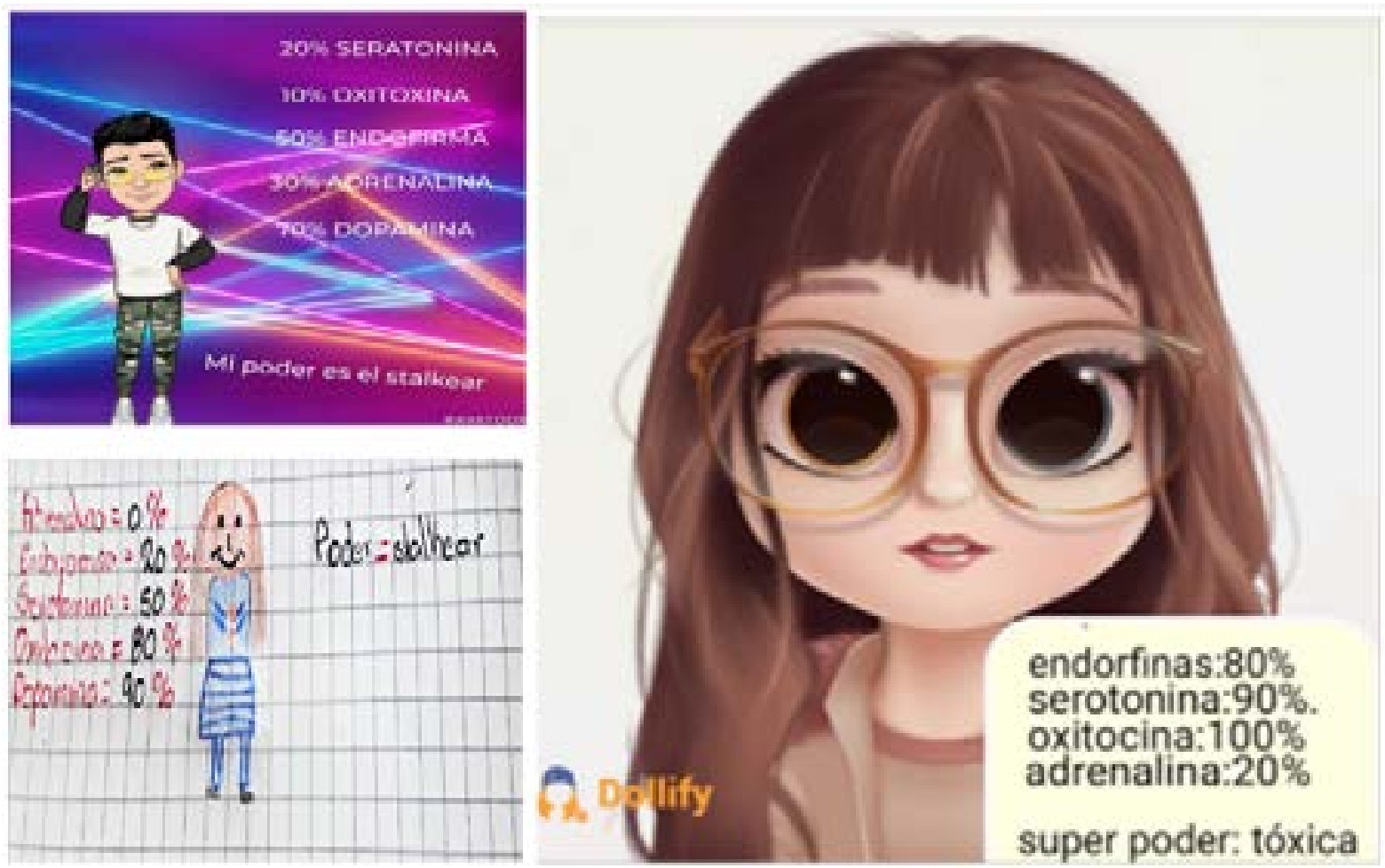

Fuente: Construcción estudiante E03- H, E07-M y E08-M

Los estudiantes de este grupo conciben como un atributo positivo y que les da ventaja en una relación, ser tóxicos - stalkeadores. Sin embargo, es importante reconocer las bases en las que se cimientan estas terminologías. Para este caso, partimos desde el concepto de amor, ya que, a lo largo de la historia, ha tomado diversas perspectivas. Destaca la teoría propuesta por John Lee, en la que se establecen un estilos de amor y respecto a cada uno se dan diferentes tipos de relaciones. Un estilo que encaja en nuestras descripciones se denomina manía, se caracteriza por considerar a la pareja como un objeto o posesión, lo que conlleva una alta presencia de celos y necesidad de demostraciones de amor (Robles, et al. 2021).

Considerar a la pareja como alguien de su propiedad, instaura una figura de dominación sobre el otro y haciéndolo sumiso de quien ejerce el poder. Esto le deniega poder de decisión y actuación sobre la relación. A esto se le denomina ser tóxico (Sierra y Godoy 2019). Quien desarrolla una relación tóxica sobre otro, replica acciones de agresión psicológica y física, que tienen origen en características interpersonales antisociales como la ira, depresión, trastornos de personalidad, problemas de manejo de sustancias, intentos de suicidio y problemas de autoestima (Rubio, et. al.,2015).

Sumado a esto, las relaciones tóxicas y las violencias que replican pueden emularse de un sistema familiar en donde se aprendieron dichas conductas (Galicia, et. al., 2013). En este sentido, para los estudiantes de este grupo, es natural asumir una postura de control en una relación, porque ya está tan normalizado en su contexto y probablemente reproduzcan estos comportamientos en sus experiencias propias. (Soldevila, et, al, 2012). 
En el contexto actual, donde es muy sencillo acceder a la información personal de otros, ejercer control sobre las acciones de la pareja se puede hacer de manera práctica usando el stalkeo. Hinduja y Patchin (2011) describen stalkear, como una actividad de vigilancia sobre alguien de la pareja, en sus redes sociales, así como en el uso del celular. El stalkear se ha vuelto una actividad cotidiana entre los adolescentes. Al parecer no pierden la ocasión, por mínima que sea, para averiguar qué hace el otro

No obstante, esta obsesión por estar al tanto de todos y cada uno de los movimientos de la pareja en las redes sociales, ocasiones fricciones, debido a que este stalkeo es contundente y no deja espacios de interacción social, que el ser stalkeador no conozca (Reyes, 2017). Adicionalmente dos estudiantes de este grupo consideran el stalkeo como una súper habilidad ya que se debe tener cierta nivel astucia para llevarlo a cabo, para que este no se de cuenta tan directamente que está siendo vigilado (Hinduja y Patchin, 2011). Por último, solo uno de los estudiantes de este grupo definen como super poder, hacer feliz a la persona que esté conmigo, coincidiendo con la clasificación de López, et. al., (2011) que establecen algunos adolescentes se entregan por completo en su relación

Sin embargo, este súper poder que relaciona la estudiante puede ser contraproducente, si bien se desea el bienestar para el ser amado, dar cuidados al otro, darse y dar de sí aquello que se cree beneficia a la pareja. No es esperar del otro, en una postura pasiva, o de recompensa, es simplemente dar (Blandón y López, 2016). O tomar una postura de complacencia absoluta en donde la persona con frecuencia subordina sus propias necesidades y ceden en sus puntos de vista, para no desagraviar al (la) compañero (a), entrando así en una relación tóxica, convirtiéndose en una persona sumisa y víctima de las violencias en la relación (Cedeño y Valdés, 2016; Sierra y Godoy 2019)

\section{GRUPO CATEGORIAL LA PARLA}

De otra parte, los estudiantes relacionan como otra super habilidad, la parla. La parla es un término del lenguaje coloquial en Colombia, que refiere a usar habilidades comunicativas que permitan transmitir a la persona de interés, la atracción sentida, que después posibilite entablar una relación amorosa. 

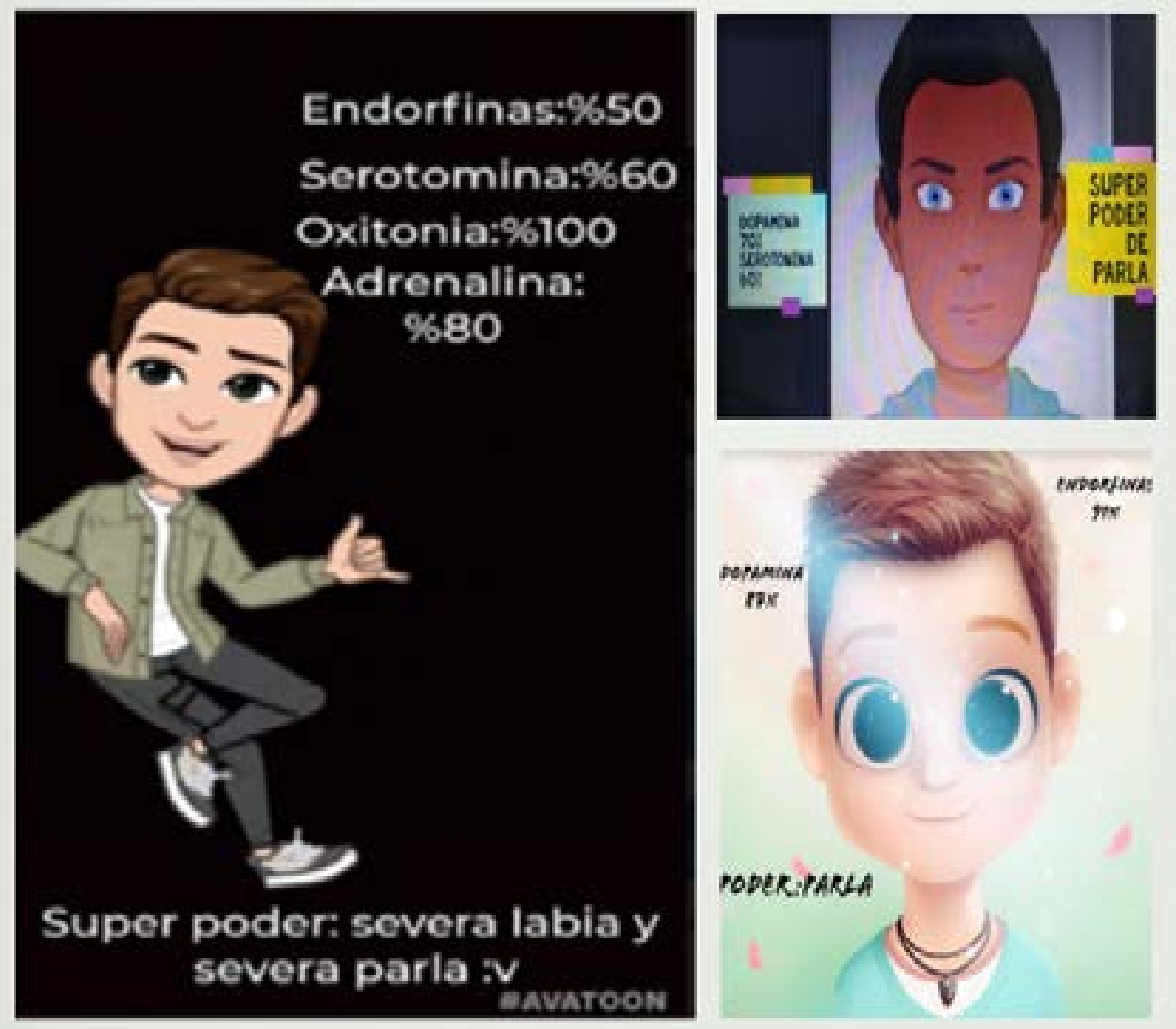

Fuente: Construcción estudiante E05- $\mathrm{H}, \mathrm{E} 06-\mathrm{H}$ y E09- $\mathrm{H}$.

La parla entonces se convierte en un mecanismo para seducir a alguien, pues es un discurso cargado de elogios que halagan a la persona sobre su forma de vestirse, actuar y pensar. También discurre al acto detallista mostrando a un pretendiente interesado y cortés, pero como lo define Baudrillar, es una acción de seducción de ilusión, en la que la persona se desvía de su propia verdad, se convierte en el modelo del amor y se adapta a las condiciones de la persona que corteja. Consiguiendo así establecer una relación, pero cuando todo el acto seductor se termina, se revela la personalidad original (Baudrillard, 2000, citado en Aqueveque, 2019). En este sentido, algunas mujeres andan prevenidas sobre estas formas de seducción de ilusión, que pueden resultar en desacuerdos y engaños. Aspecto que se relaciona con el súper poder que le coloca a su avatar una estudiante de este grupo, designándolo como poder de selección 


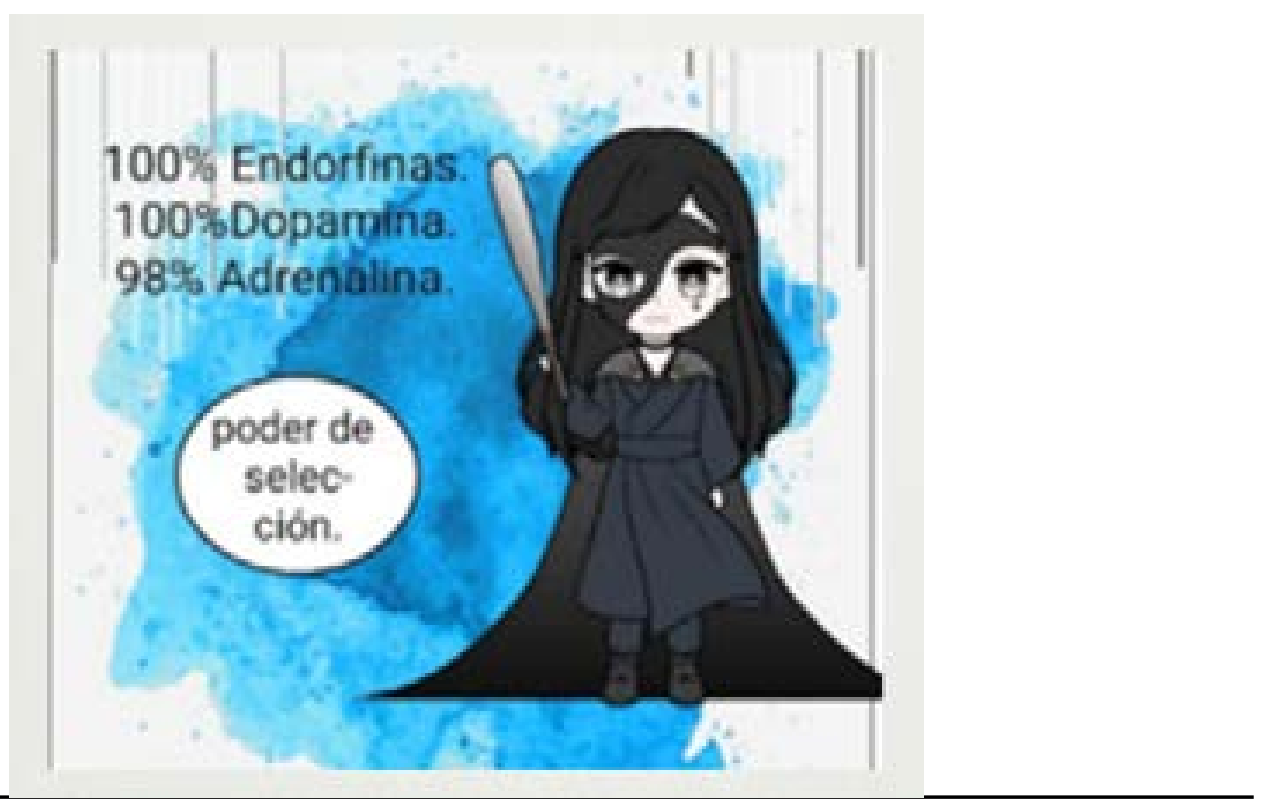

Fuente: Construcción estudiante E12-M.

El poder de selección como lo menciona la estudiante, es la escogencia de la pareja de acuerdo con criterios personales. Sin embargo, estos se ajustan a las necesidades psicológicas de la persona y están influenciados por los espejos que tienen de sus parentales (Estrada y Moran, 2014). Algunas mujeres tienen tendencia a escoger personas como indicador de buena salud, educación, voluntad de establecer una relación comprometida y personas con una edad mayor que la de ellas, ya que tienen mayor madurez que sus pares de la misma edad (Russock 2011; Anderson y Klofstad, 2012). La estudiante cuando evoca este superpoder espera hacer una selección en concordancia con estos preceptos y buscando la configuración de lo que pudiera ser una pareja que se desempeñe como protectora (Gozalo, 2013).

\section{EXPERIENCIAS DE AMOR ADOLESCENTE}

A continuación, presentamos algunas experiencias entorno a la categoría enamoramiento y relaciones románticas que han vivido los estudiantes. Destaquemos en primer lugar, el caso de una estudiante que describe una experiencia amorosa con su mejor amiga, donde ella tenía una relación de pareja.

Yo tuve un tipo de relación con mi antigua mejor amiga, nosotras nos dábamos besos tiernos y algunos con deseo y después llegó la causa de mis celos y la razón por la que rompimos todo contacto y (yo estaba en quinto en es momento) ella parecía interesada en esa persona entonces yo le dije lesbiana ella se enojó y terminamos alejándonos y yo obviamente me sentí mal, me gustaría haberme confesado, después tuve otra "relación" donde tenía un mejor amigo que me decía "cupido" porque lo ayude a tener a la más bonita del salón pero también termine enamorándome de él y nunca se lo dije porque no quería arruinar nuestra relación ya que era una persona físicamente "fea". (E01-M, 13 años)

Al respecto, Echeverría-Lozano y Villagrán (2015), consideran que el deseo sexual forma parte importante en nuestro desarrollo, es en la adolescencia donde se manifiesta con mayor 
intensidad, donde se configuran nuestros vínculos emocionales y el cuidado de nuestra salud (sexual y reproductiva) y se deja de lado el placer, el gozo del propio cuerpo y la responsabilidad de éste

Continuando con la narración de esta estudiante, se menciona un momento de fractura en su relación cuando su compañera se ve interesada por otra persona, haciendo surgir en ella actitudes negativas y celos de esta tercera persona. Según Ardila (2017), cuando uno ama, tiene miedo de perder el amor del otro, por lo cual la pareja considera que el otro es atractivo para sí y para otro posible rival. Ahora bien, para Estebanez (2010), los celos tienen que ver con el comportamiento de control que puede desencadenar en situaciones de violencia. Al respecto, para Bittar y Nakano (2017), mencionan que aún se tiene una percepción errónea sobre los celos ya que se consideran que juegan un rol de demostración de amor, de modo confundido y llega a ser una justificación para la violencia

Igualmente, la estudiante menciona que ejercía violencia contra su amiga debido a los celos, utilizando un sentido negativo de su orientación sexual para lastimarla psicológicamente. Como plantean diversos autores, en casos de violencia psicológica la persona es tratada por medio de insultos, amenazas, ofensas, gritos, críticas, donde se le discrimina y descalifica al hacerle notar que no vale y que carece de derechos o atenciones (Vivanco et. al., 2015). En este sentido, Vergara (2019), encontró que la violencia ejercida en las relaciones de enamoramiento en adolescentes, sobresale la violencia verbal donde el sexo femenino destaca como agresoras en su relación amorosa usando las amenazas y la violencia verbal-emocional.

Cabe destacar que la violencia entre parejas jóvenes del mismo sexo es casi invisible en la investigación, debido a que la temática de las minorías sexuales ha sido poco estudiada a nivel académico. Sin embargo, se identifica a los jóvenes de estas minorías como quienes sufren con mayor frecuencia violencia de pareja. Esto, pone en situación las actitudes negativas sobre las relaciones de pareja, que pueden desembocar en otros problemas de salud y de orden social en etapa adulta (Saldivia, et. al., 2017)

Un aspecto importante en la narrativa del estudiante, es cuando se enamoró de su amigo, no lo acepta porque "era una persona físicamente fea" expresión que manifiesta estándares de belleza no valida por el entorno vivido, por lo cual nunca declaró lo que sentía por él. Aquí, los trabajos de Duno y Acosta (2019) sostienen que durante la adolescencia la apariencia física es uno de los temas de mayor preocupación y está determinada por factores internos y externos, por el género y por las normas de belleza de la sociedad. En ese mismo contexto, se encuentra relación con lo encontrado por Casullo (2004) entre los adolescentes en el rango de 13 a 15 años, donde el atractivo físico juega un papel importante en la búsqueda de pareja y cómo esta influye en la percepción que tienen de ellos sus pares

Por otra parte, para la estudiante del caso, el gusto físico pasa a un segundo plano, dando lugar a la posibilidad de recibir atención, cariño, y vivir experiencias. Situación que Sánchez et al., (2011), destaca al identificar la alta valoración que los adolescentes asignan en un (a) novio (a) con respecto a su capacidad de dar afecto y sinceridad en sus sentimientos, por encima incluso de la apariencia física.

En segundo lugar encontramos el relato de otro estudiante asociado a las relaciones basadas inicialmente en gustos compartidos:

Todo comenzó por una amiga que tenia en mi conjunto y pues ella me dijo que si la quería conocer y yo le dije que bueno, ella me paso el contacto y comencé a 
hablar con ella y bueno vi que ella pues teníamos varias diferencias el tipo de comidas y en la música a ella le gustaba es rock y a mi el reggaeton.

Después de un mes o dos meses que la conocía bueno me comenzó a atraer $y$ pues yo tambien a ella entonces entonces cuadramos un día para salir entonces todo iba bien después nos despedimos y normal después de un mes aparecio mi ex a inventarse unas cosas ahí que no eran verdad luego de un mes volvieron los disgustos y pues bueno terminamos y esa fue mi historia de amor (E05-H,15años)

Aquí el estudiante, en su historia de enamoramiento, hace referencia a la importancia de compartir gustos parecidos con la persona con la que se desea tener una relación romántica. Como plantea Sánchez (2009), los adolescentes esperan similitud y complementariedad en gustos, actividades con su pareja y que su vida social sea compatible. Asimismo, BlandónHincapié y López-Serna (2014) sostienen que compartir gustos parecidos solo es importante en una fase del enamoramiento denominada acercamiento. En esta etapa los adolescentes la describen como una experiencia difícil porque hay diferencias entre los miembros de la pareja que se tornan complejas dentro de la interacción, como los temperamentos, las maneras de ver las cosas, las expectativas que cada uno espera de la relación y del otro.

Siguiendo con el relato del estudiante, se menciona también la idea de atracción mutua. Ésta, así como el amor, la confianza y la simpatía surgen como los criterios más importantes para la elección de una pareja romántica, generando actitudes positivas hacia este tipo de relaciones por parte de los adolescentes (Casullo, 2004). En efecto, de acuerdo con Zegarra (2015), en el proceso de enamoramiento suele comenzar con una atracción física inicial hacia otra persona, transformándose posteriormente en las intenciones de tener sexo, un ejemplo de esto es la alocución del estudiante cuando se le pregunta ¿cuales son las ventajas de tener novi@? Y comenta:

Jajajajajaja...pos más posibilidades de hacer el delicioso(E06- H,15 años)

Asimismo, alude que la ruptura de su relación amorosa, se debió a los chismes que generaba su ex pareja, los cuales generan peleas y disgustos. Esto coincide con lo reportado por Barajas et. al., (2012) , quienes señalan como causas más frecuentes de una ruptura la infidelidad, el engaño, las faltas de respeto, los maltratos, las peleas, la intolerancia y los chismes

Una ruptura de noviazgo para los jóvenes es importante, dado el impacto que ésta puede tener sobre la salud física y mental del individuo, así como en la posibilidad de prevenir sus consecuencias negativas e incidir de manera efectiva, por lo cual diversos autores se han ocupado de investigar las consecuencias de este evento en la salud física y mental de un individuo (Barajas et al.,2012) (Urrelo, 2015).

Mientras tanto, un tercer caso, se encuentra en otro estudiante que menciona que él tenía una relación romántica con una niña y afirma que esta relación era muy bonita cuando comenzó pero que con el tiempo género experiencias insatisfactorias:

Pues yo tuve una relación con una niña pues no era tóxica pero tampoco sana yo terminé con ella pues por darnos un tiempo por algo, pero fue muy bonita en su tiempo (E09-H,14 años)

Situación que se relaciona con lo planteado por Rocha, Avendaño, Barrios y Polo (2016), expresan que enamorarse, es un sentimiento vinculado con el afecto y el apego que en muchas 
ocasiones y dependiendo de la situación puede volverse positivo o negativo. Respecto de estos últimos, distintos estudios han encontrado que la mayoría de personas que sufren experiencias negativas en pareja lo mantienen en secreto, los estudios en adolescentes y jóvenes destacan las aportaciones realizadas por González Méndez y Santana Hernández (2001), quienes informan que los hombres y las mujeres reconocen que en una o más ocasiones han pegado o empujado a su pareja.

\section{MANTENIENDO EL VÍNCULO}

En otro caso, un estudiante, cuenta que cuando él se enamora:

Pos si he vivido alguna de esas historias porque cuando yo me enamore tambien me pasaba lo mismo le daba regalos cartas y todo eso etc. (E6- H,15años)

Para Aragón (2009), los adolescentes suelen proveer regalos y atenciones a su pareja con los cuales expresan frecuentemente su amor, se comunican mejor y sorprenden más al otro, con esto tienden a sentir más estabilidad y seguridad de su pareja. Hernando-Gómez, MaraverLópez, \& Pazos-Gómez (2016), relacionan las muestras de cariño y apoyo con los regalos, que para suelen ser parte de las experiencias positivas que recuerdan los adolescentes durante el noviazgo, para las mujeres es mucho más frecuente relacionar este tipo de conductas con experiencias positivas, mientras que para los hombres el dar regalos a su pareja fortalece los lazos entre estos, dándole un carácter cada vez más o menos seguro a esa relación.

\section{AMISTAD Y NOVIAZGO}

De igual importancia, la amistad es un vínculo afectivo que va posibilitando el establecimiento de una relación de pareja, los jóvenes dan relevancia a algunas características que se viven con intensidad en el noviazgo como "el afecto, el amor benevolente, la confidencialidad, la participación en ideales comunes todo ello podrá dar cuerpo a una relación de amistad" (BlandónHincapié y López-Serna, 2014). Por ejemplo en la narración de la siguiente estudiante esta ayuda a su mejor amigo, fingiendo ser su novia pero el sentimiento de amistad se transforma en amor y terminan en una relación romántica verdadera

Pues al principio todo fue por ayudar al chino porque una nena lo jodia mucho $y$ pues el no quería nada con ella me pidió el favor de que hiciéramos como una relación falsa para que la nena no molestar y pues ya se volvió en serio pero pues era súper sana porque era del salón y pues éramos re uña y mugre pero en el descanso pues él con sus amigos y yo con los míos, pero pues no funcionó porque era mejor como amigos pero terminamos re bien y ya. (E04M. 13años)

En un estudio realizado por Blandón-Hincapié y López-Serna (2014), encontraron que los jóvenes hacen referencia a los cimientos de sus relaciones de pareja, mencionan que se dio por medio del cortejo, a través de una amistad. Existen por lo tanto las amistades que trascienden a vínculos amorosos, que sin pretender al inicio tener algo con esta persona, la amistad, el compartir, el conocer al otro como alguien confiable, compatible, permite el surgimiento de un sentimiento, una atracción que deviene en relación de noviazgo. En este aspecto, Rocha et al., (2017) plantean este tipo de relaciones como amor compañero es una unión incondicional entre dos partes, que se guardan protección y cuidados, procurando su mutuo bienestar y expresión de afecto físico.

Cuando la estudiante plantea que era una relación sana al contrario de las experiencias de otros de sus compañeros, narra que seguían frecuentando a sus compañeros y compartiendo de forma individual con estos. En lo atinente, 
Estebanez (2010), remarca la importancia de los grupos de amistad durante el noviazgo, de seguir manteniendo amistades propias no sólo amistades comunes con la pareja, protege contra el aislamiento social que puede desencadenar en actitudes negativas así las relaciones de pareja

\section{SENTIMIENTOS Y SENSACIONES}

Soriano-Ayala et. al., (2014) describen que la reacción de los adolescentes cuando muestran sus sentimientos ante otro oscilan desde estados de alegría, felicidad y sentirse bien, a estados fisiológicos como adrenalina desbordada, cosquilleo en el estómago, dar saltos de alegría, como se aprecia en lo declarado por la estudiante:

Cuando me gusta alguien tengo adrenalina porque me gusta pero disimulo, a veces aparento que no me gusta para que no sospeche pero nunca me atrevo a decir nada, a veces al ver que no me interesa terminan enamorándose de otra persona y pues me doy cuenta que lo perdí o a-veces esa persona no siente lo mismo que tu y solo te ve como una amiga y no más. (E10$M$, 13años)

En este mismo sentido, la estudiante expresa que no muestra interés en alguna persona. Massa (2011), resalta que las mujeres muestran mayor prevención en el proceso de involucrarse en una relación que implique intimidad emocional y psicológica, lo cual, puede deberse al alto impacto que tiene sobre el desarrollo de la identidad de las mujeres el éxito o fracaso en las relaciones afectivas así como el miedo al rechazo

Por otra parte, encontramos que no todos los estudiantes no han tenido una relación romántica (noviazgo) contraria a lo que esperábamos, pero sí es evidente que durante la adolescencia los estudiantes comienzan a sentirse interés romántico por personas diferentes a las de su núcleo familiar. Por ejemplo, el caso de la estudiante que declara: No he tenido historias de amor pero una vez me enamoré de una persona pero él ya tenía una novia, para los adolescentes el noviazgo es concebido como una relación que se toma en "serio", en la que hay confianza, apoyo, comprensión, sinceridad, fidelidad, afinidad y unión y el la cual debe ser respetada por terceros (Sánchez et al.,2010).

\section{PERCEPCIONES DE RELACIONES ROMÁNTICAS EN ADOLESCENTES}

En este aparte se muestran los resultados del cuestionario aplicado, partiendo de la observación de un vídeo y la narración de relaciones románticas. Los estudiantes respondieron lo que opinaban sobre dichas situaciones, en los gráficos se relacionan las respuestas dadas por los estudiantes a unas preguntas dinamizadoras formuladas por las docentes, en virtud de las imágenes y vídeos vistos

\section{SECCIÓN 1: L POSITIVO Y LO NEGATIVO}

En esta sección 1, los estudiantes 30, 1 y 22 mencionan aspectos negativos en las relaciones románticas que reconocen en los videos que son la infidelidad y toxicidad. Como plantean Hernando-Gómez, Maraver-López, y Pazos-Gómez (2016), de las experiencias negativas vividas más frecuentemente por los adolescentes en relaciones románticas se identifican "la infidelidad" problemáticas que bien pueden suponer el inicio de una situación violenta. Los estudiantes consideran que la infidelidad puede ser un factor de riesgo, pues su presencia puede generar actitudes negativas hacia el amor ( q el amor es malo porque les ha ido mal con su pareja) 
Fig. 7 Las relaciones que viste en los videos y que planteaste, en el ejercicio previo, se relacionan explica tu respuesta

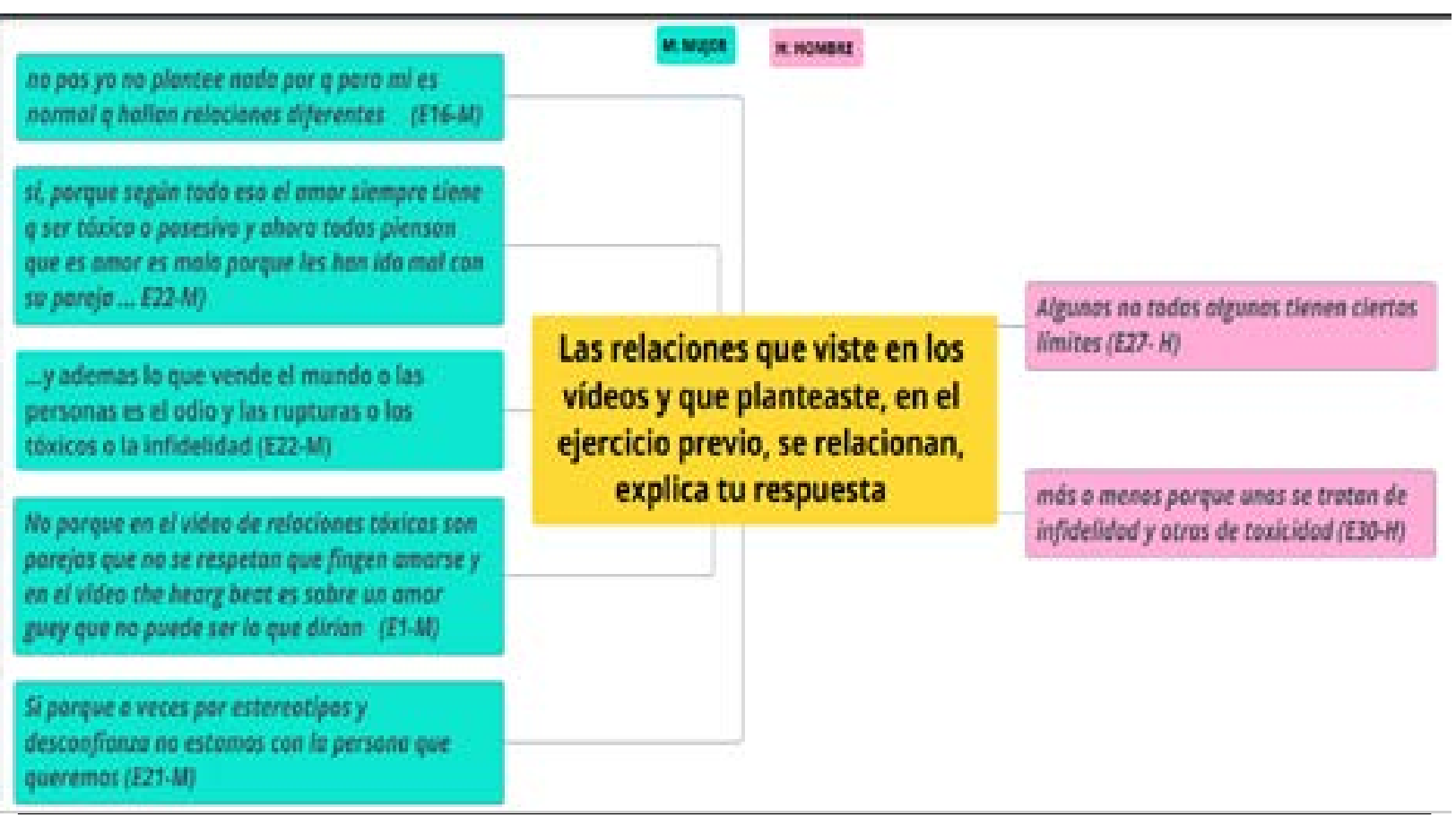

Fuente: Creación propia

Retomando la expresión "relaciones tóxicas" que utilizan los estudiantes para señalar las vínculos de poder o con violencia que son frecuentes durante la adolescencia y que como menciona la estudiante \# 6 se suelen relacionar de forma arbitraria con un modelo de amor. De acuerdo con Granados (2018), una relación tóxica enlaza estilos de apego inseguro, donde se encuentran comportamientos de celos y control, recalca la importancia de un proceso de socialización en el que se promuevan los factores de protección, donde los adolescentes aprenden a relacionarse de forma adecuada y a respetar a los demás, generando actitudes positivas así las relaciones de pareja. 
Sección 2. Amor, poder y realidad

Fig. 8 ; Crees que sea una situación real?

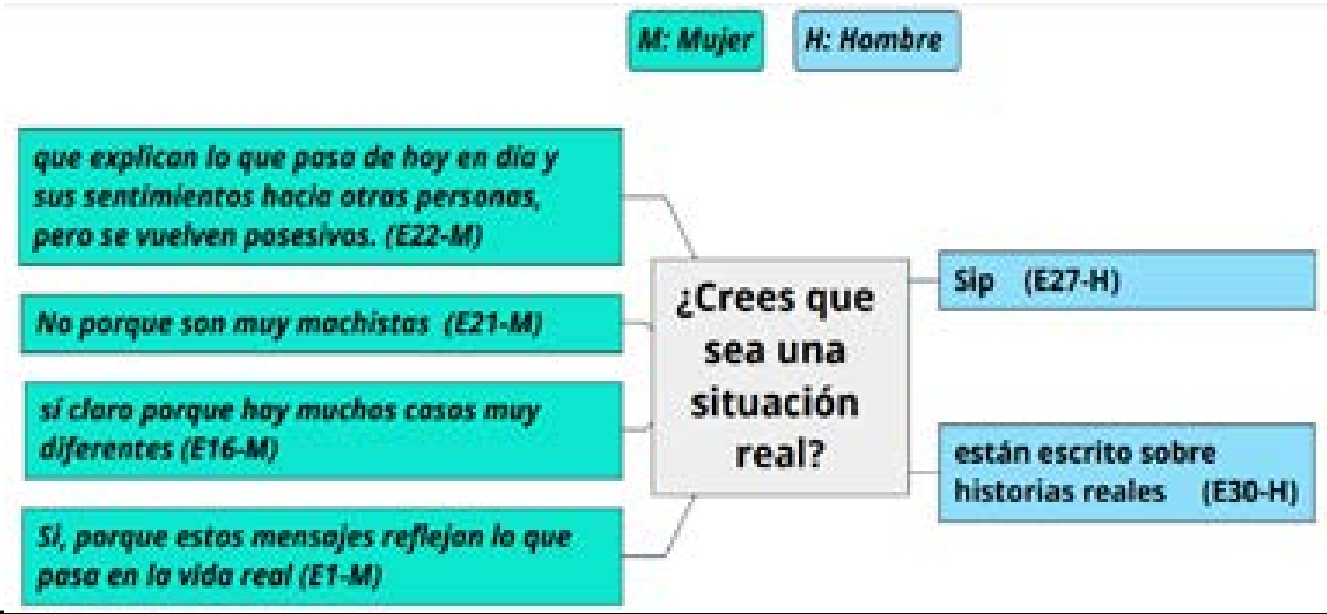

Fuente: Creación propia

En las declaraciones, los estudiantes afirman que las situaciones expuestas en los videos son reales. La estudiante \# 22 destaca que estas experiencias son comunes en la actualidad, donde las personas tienen relaciones de posesión con sus parejas.En el trabajo realizado por Hernando-Gómez, Maraver-López, \& PazosGómez (2016) donde abordan las experiencias vividas en pareja adolescentes, encontraron que los adolescentes tienen relaciones de poder que pueden desencadenar en violencia psicológica o verbal.

Sufrimiento y violencia

Fig 9 ¿Qué harías si fueras la protagonista a el protagonista de la historia?

\begin{tabular}{|c|c|}
\hline 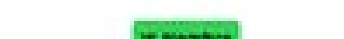 & Pues depende come es lo persone \\
\hline \multirow{3}{*}{$\begin{array}{c}\text { ¿Qué harias si fueras } \\
\text { la protagonista o } \\
\text { protagonista de la } \\
\text { historia? }\end{array}$} & Pues es normal (E30-H) \\
\hline & $\begin{array}{l}\text { Yo Hubiera rerminedo can esa relocibn pare no seguir } \\
\text { sufrieado (ET-M] }\end{array}$ \\
\hline & $\begin{array}{l}\text { Pues bay no se puede hocer nodo par que une ao decide } \\
\text { de quilen se enomora (E16-M) }\end{array}$ \\
\hline & $\begin{array}{l}\text { Lo verdod, pues of fiool, uno slempre se do cuenta que } \\
\text { wale mucho (E2T-M) }\end{array}$ \\
\hline Me 140 & 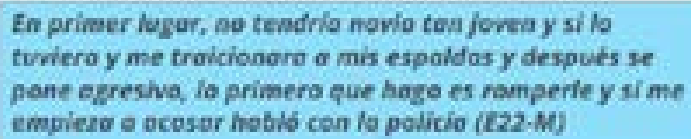 \\
\hline
\end{tabular}


Cuando se les pregunta a los estudiantes sobre la historia de la figura\# y que harian en esa situación encontramos respuestas divididas. Los estudiantes 27, 30, 16 y 21 no identifican la situación como violencia psicológica, mientras que los estudiantes 3 y 6 declaran que es una situación que puede generar sufrimiento y que debe terminar con la relación. Según Estebanez (2010) existen dificultades para que las chicas adolescentes perciban con claridad las situaciones de violencia porque durante la adolescencia mantienen sus primeras experiencias afectivas y tienen un conocimiento irreal o idealizado sobre el amor, influido por la cultura del amor romántico que se transmite en la música, las revistas juveniles o las series de televisión

La estudiante \#5 resalta la importancia de valorarse como persona, esto lo podríamos identificar como una actitud de cuidado consigo mismo, cuando se tiene una relación romántica. Por otro lado la estudiante \#6 menciona que aun es muy joven para establecer un noviazgo pero que estando en un situación como la narrada, donde se generan agresiones o violencia de cualquier tipe esta_acudiera_a a la policía.

Finalmente los estudiantes 27, 30, 1, 16 y 22 mencionan que hasta el momento no han vivido y visto una situación similar a la de la historia. La estudiante \# 21 afirma si a ver tenido una experiencia similar donde la persona con quien salía, la engañaba y lastimaba psicológicamente. Estebanez (2014), resalta que para los adolescentes el noviazgo es una lucha entre la cabeza y el corazón, la idealización sobre el amor como algo que va unido al sufrimiento y el esfuerzo, y la idea del amor como elemento que puede reparar cualquier daño ocasionado, confunde y engaña a estas chicas llevándolas a aceptar situaciones violentas. Es importante destacar que la estudiante declara haber salido de esta situación y que le permite generar en ella una actitud de reconocimiento y cuidado de ella misma

\section{Fig. 10; Han vivido una situación familiar?}

\begin{tabular}{l|l|l|}
\hline No, no conozco ninguna relación (E1-M) & $\begin{array}{l}\text { Pues yo estuve con - y el fue } \\
\text { muy malo y era aigo tóxica y me } \\
\text { estaba dañando a mi, pues } \\
\text { porque era muy perro y, en fin, al } \\
\text { final yo me di cuenta y ya. (E21-M) }\end{array}$ \\
\hline $\begin{array}{l}\text { No, no conozco ni he tenido solo una } \\
\text { vez que un tipo estaba enamorado de } \\
\text { mi y yo no le acepté el noviazgo... me } \\
\text { amenazo con cortarse o suicidarse y yo } \\
\text { le dije que hiciera lo que quisiera y al } \\
\text { final no se mató sino que se fue con } \\
\text { otra muchacha (E22-M) }\end{array}$ & $\begin{array}{c}\text { SHAN VIVIDO } \\
\text { UNA }\end{array}$ & FAMILIAR? \\
\hline
\end{tabular}

Fuente: Creación propia.

La estudiante \#22 narra una experiencia donde estaba siendo amenazada por un compañero. Algunos adolescentes utilizan la amenaza de atentar contra la integridad física de ellos o de compañero sentimental, para garantizar que este permanezca en la relación amorosa o comience una como narra la estudiante 22 , esto es una muestra de control o el dominio de un miembro de la pareja (Rivera, 2016). También se debe resaltar que la estudiante no ve esta situación como violenta y esto se repite en varios estudios sobre relaciones románticas en la adolescencia, esto se debe a que muchos adolescentes creen 
que sólo existe violencia física como lo son los golpes, pellizcos, empujones, entre otras cosas.

\section{CONCLUSIONES}

Los procesos de interacción entre adolescentes ilustran formas de asumir el enamoramiento, en este sentido se evidencia que para los adolescentes debe haber un escalamiento en la forma de amarse y aceptación en el grupo social: primero se debe ser amigos para luego denominarse novios.

Los avatares construidos por los estudiantes permitieron identificar las características ideales que cada estudiante concibe importantes para entrar en una relación. Sin embargo, casos como las categorías parla, tóxica - stalkear, exaltan como súper poder, atributos que en la relación terminan siendo poder y dominación sobre otro.

Particularmente, en la categoría parla, se encuentra que es mediante el uso de palabras convincentes como se permite establecer relaciones con otras personas. Ahora bien, la comunicación asertiva, es indispensable en una relación pero mucha de la denominada parla, exagera o genera situaciones que ocultan la verdad del pretendiente.

Es importante reconocer que estos poderes especiales mencionados, son normalizados en su contexto y por tal, los estudiantes los asumen como benéficos y por ende, practicándose en sus propias experiencias.

Los relatos de los estudiantes muestran que naturalizan en sus propias experiencias amorosas, las relaciones de poder y no las consideran como algo negativo, comparando estos resultados con otros estudios en adolescentes universitarios, la prevalencia de estas actitudes de violencia podría escalar en edades adultas hasta generar agresiones físicas a_sus parejas
Las experiencias vividas por los estudiantes permiten evidenciar que estos tienen actitudes positivas hacia el cuidado de ellos mismos y de sus pares cuando están en un noviazgo. Las adolescentes afirman saber cómo actuar en una situación de agresión física o psicológica, contrario a lo que se encuentra reportado en la literatura, donde las adolescentes suelen tener un papel de sumisión frente a su pareja

\section{REFERENCIAS.}

Abarca, A., Alpízar, F., Sibaja, G. y Rojas, C. (2013). Técnicas cualitativas de investigación. San José, Costa Rica: UCR

Alberoni, F. (1997). El primer amor. Barcelona: Gedisa

Alberoni, F. (2008). Lecciones de amor: doscientas respuestas acerca del

amor, el sexo y la pasión. Madrid: Gedisa

Alfonso Figueroa, Lianet, \& Figueroa Pérez, Loanys. (2017). Conductas sexuales de riesgo en adolescentes desde el contexto cubano. Revista de Ciencias Médicas de Pinar del Río, 21(2), 143-151. Recuperado en 19 de mayo de 2021, de http://scielo.sld.cu/scielo. php?script=sci_arttext\&pid=S15631942017000 $200020 \& \ln g=e s \& \ln g=e s$

Anderson, R. \& Klofstad, C. (2012). For love or money? The influence of personal resource pressures on human mate preferences. International Journal of Behavioral Biology 118(9), 841-849. doi:10.1111/j.1439-0310.2012.02077x

Aqueveque, L. T. (2019). Baudrillard. Filosofía de seducción. Revista Humanidades: Revista de la Escuela de Estudios Generales, 9(2), 139148. Recuperado de: https://dialnet.unirioja.es/ servlet/articulo?codigo $=7019015$

Barajas, M. W. y Cruz, C. (2017). Ruptura de la pareja en jóvenes: factores relacionados 
con su impacto. Enseñanza e Investigación en Psicología, 22(3), 342-352. Recuperado de: https://www.redalyc.org/pdf/292/29255775008. pdf

Bateson, G. (1998). Pasos hacia una ecología de la mente. Buenos Aires, Argentina: Ediciones Lohlé-Lumen. Recuperado de: https://pedropeixotoferreira.files.wordpress. com/2014/03/bateson-gregory-passos-haciauna-ecologia-de-la-mente pdf

Blandón-Hincapié, A. I. \& López-Serna, L. M. (2016). Comprensiones sobre pareja en la actualidad: jóvenes en busca de estabilidad. Revista Latinoamericana de Ciencias Sociales, Niñez y Juventud, 14 (1), pp. 505-517. Recuperado de: http://www.scielo.org.co/pdf/ rlcs/v14n1/v14n1a35.pdf

Bittar DB, Nakano AMS. Symbolic violence among adolescents in affective dating relationships. Rev Esc Enferm USP. 2017;51:e03298. DOI: http://dx.doi.org/10.1590/ $\underline{\mathrm{S1980-220 \times 2017003003298}}$

Calvillo, A.J. y D. Mart'ın (2017). The Flipped Learning: Gu'ıa "gamificada"para novatos y no tan novatos. Universidad Internacional de La Rioja (UNIR Editorial)

Caycedo E., Claudia, Cubides, Ingri, Martín, Angie, Cortés, Omar Fernando, Berman, Steven, Oviedo, Ana María, Suárez, Ingrid (2007). Relación entre el género y lasexperiencias de cortejo y actitudeshacia las relaciones románticas enadolescentes bogotanos. Psicología desde el Caribe, (20),76- 92. [fecha de Consulta 3 de Abril de 2021]. ISSN: 0123417X. Disponible en: https://www.redalyc.org/ articulo.oa?id $=21302005$

Casullo, M. M. (2004). Elección de pareja en adolescentes y adultos jóvenes. Psicodebate, 4 , 39-56. https://doi.org/10.18682/pd.v4i0.493
Cedeño, E. H., \& Valdés, S. L.(2016). INFLUENCIA DE LA ASUNCIÓN DE LA PARENTALIDAD EN EL FUNCIONAMIENTO DE UN GRUPO DE PAREJAS. Alternativas cubanas en Psicología, 57. Recuperado de: https://www.researchgate.net/profile/AmarilysTorrado-Ramos/publication/338778114 ESTUDIO PSICOLOGICO DE LA ABUELIDAD EN ADULTAS MAYORES RESIDENTES EN LA CAPITAL CUBANA/ links/5e29dc4d92851c3aadd50b80/ESTUDIOPSICOLOGICO-DE-LA-ABUELIDAD-ENADULTAS-MAYORES-RESIDENTES-EN-LACAPITAL-CUBANA.pdf\#page $=59$

Denzin, N y Lincoln, Y.(1994). Handbook of Qualitative Research London: Sage Publication. Recuperado de: https://www.redalyc.org/ pdf/623/62320212.pdf

Echeverría-Lozano, Alejandra, \& Villagrán Vázquez, Gabina (2016). El contexto y la experimentación del deseo sexual en jóvenes: diferencias entre hombres y mujeres. Psicología Iberoamericana, 24(1),19-29. [fecha de Consulta 23 de Marzo de 2021]. ISSN: 1405-0943. Disponible en: https://www.redalyc.org/articulo. oa?id $=133947583001$

Estrada Palencia, J. A., y Moran Ortiz, R. A. (2014). Construcción asertiva de las relaciones de pareja en la adolescencia (Doctoral dissertation, Universidad de San Carlos de Guatemala). Recuperado de: http://www.repositorio.usac. edu.gt/9392/1/T13\%20\%282782\%29.pdf

Eisele-Dyrli,K.(2011). "MobileGoes Mainstream". En: District Administration 47.2, p'ags. 46-55. Recuperado de: https://www.researchgate. net/publication/318403675 Combinacion de cuestionarios simples y gamificados utilizando gestores de participacion en el aula experiencia y percepcion del alumnado 
Galicia, I., Sánchez, A. \& Robles, F. (2013). Relaciones entre estilos de amor y violencia en adolescentes. Psicología desde el Caribe, 30 (2), 211-235. Recuperado de: http://www. redalyc.org/articulo.oa?id $=21328601002$

Gozalo, R. (2013). Preferencias de pareja segúnla orientación sexual: un análisis desde la psicología evolucionista (Tesis de licenciatura). Pontificia Universidad Católica del Perú. Recuperado de: http://tesis.pucp.edu.pe/repositorio/ bitstream/handle/20.500.12404/4899/ GOZALO_BOHL_RODRIGO PREFERENCIAS_EVOLUCIONISTA. pdf? sequence $=1$ \&isAllowed $=y$

Hernando-Gómez, A., Maraver-López, P., \& Pazos-Gómez, M. (2016). Experiencias positivas y negativas en las relaciones de pareja de jóvenes y adolescentes. Revista de Psicología, 25(2), 1-19. http://dx.doi.org/10.5354/0719$\underline{\underline{0581.2016 .44745}}$

Hinduja, S. Y Patchin, J. W. (2011). Electronic dating violence: A Brief Guide for Educators and Parents. Cyberbullying Research Center http:// cyberbullying.org/electronic_dating_violence_ fact_sheetpdf

Huanca Florez, M. D. F. O. (2020). Resiliencia y violencia en el enamoramiento en adolescentes de las Instituciones Educativas. Recuperado de: http://tesis.ucsm.edu.pe/repositorio/ bitstream/handle/UCSM/10224/76.0422. PS.pdf? sequence $=1$ \&isAllowed $=y$

López, J. E. M., Escalante, Y. M. P., Keb, R., Canto, M., \& Chan, N. (2011). La definición de amor y dependencia emocional en adolescentes de Mérida, Yucatán. Revista electrónica de psicología Iztacala, 14(3), 176-193. Recuperado de: https://www.iztacala.unam.mx/carreras/ psicologia/psiclin/vol14num3/Vol14No3Art10. $\underline{\text { pdf }}$
Reyes, L. M. V. (2017). Violencia en las relaciones sentimentales: del cara a cara al mundo virtual. In XIV Congresso Nacional de Investigación Educativa (COMIE), México. Recuperado de: http://www. comie. org. $m x /$ congreso/memoriaelectronica/v14/doc/0006. $p d f$.

Narváez, B. L., Parra, C. E., Alonso, M. A., \& Madera, A. P. (2016). ACTITUDES HACIA EL AMOR EN RELACIONES ROMÁNTICAS DE JÓVENES UNIVERSITARIOS. Praxis Saber, 155-178. Recuperado de: https://revistas. uptc.edu.co/index.php/praxis_saber/article/ $\underline{\underline{\text { view/4596 }}}$

Penagos, A., Rodriguez, M., Carrillo, S., \& Castro, J. (2006). APEGO, RELACIONES ROMÁNTICAS Y AUTOCONCEPTO EN ADOLESCENTES BOGOTANOS. Univ. Psychol. Bogotá, 21-36. Recuperado de: https:// www.redalyc.org/pdf/647/64750103.pdf

RIVERA-RIVERA, Leonor et al. Violencia durante el noviazgo, depresión y conductas de riesgo en estudiantes femeninas (12-24 años). Salud pública Méx [online]. 2006, vol.48, suppl.2, pp.s288-s296. ISSN 0036-3634.

Robles, F. J., Xóchitl, G. M., Sánchez, A, y Núñez, E. (2021). Maltrato en el noviazgo y estilos de amor en alumnos de secundaria, bachillerato y licenciatura. Psicología Desde El Caribe, 38(1) Retrieved from https://search.proquest.com/ scholarly-journals/maltrato-en-el-noviazgo-yestilos-de-amor-alumnos/docview/2429010834/ $\underline{\text { se-2?accountid }=48797}$

Rubio-Garay, F., Carrasco, M., Amor, P., \& López-González, M. (2015). Factores asociados a la violencia en el noviazgo entre adolescentes: una revisión crítica. Anuario de Psicología Jurídica, 25, 47-56. Recuperado de: https:// www.sciencedirect.com/science/article/pii/ 


\section{$\underline{\mathbf{S 1 1 3 3 0 7 4 0 1 5 0 0 0 0 8 2}}$}

Russock H (2011) An evolutionary interpretation of the effect of gender and sexual orientation on human mate selection preferences, as indicated by an analysis of personal advertisements. Behaviour 148:307-323 Doi $10.1163 / 000579511 \times 556600$

Saldivia Mansilla, Claudia, Faúndez Reyes, Bárbara, Sotomayor Llanos, Sebastián, \& Cea Leiva, Fredy. (2017). Violencia íntima en parejas jóvenes del mismo sexo en Chile. Ultima década, 25(46), 184-212. https://dx.doi.org/10.4067/ S0718-22362017000100184

Sánchez, F. L. (2019). Los afectos sexuales: (3) el enamoramiento. Adolecere, 1-14. Recuperado de: https://www.adolescenciasema. org/tema-de-revision-los-afectos-sexuales-3-elenamoramiento-f-lopez-adolescere-2019-vii-3$\underline{\underline{51-e 1-51-e 14 /}}$

Serna, D. (2008). La imagen y el diseño visual en procesos investigativos. En: Revista KEPES. v. 5, n. 4 p. 179-196. Recuperado de: http://vip. ucaldas.edu.co/kepes/downloads/Revista4_10. pdf

Sierra Parra, J. A., y Godoy Pineda, C. (2019). Características y comportamientos tóxicos de las relaciones de pareja en adolescentes bogotanos. Recuperado de: https://repository.javeriana.edu. co/bitstream/handle/10554/49404/Camila\%20 Godoy \%2c\%20Jossiee\%20Sierra\%2c\%20 2019.pdf? sequence $=1$ \&is Allowe

Soldevila, A., Domínguez, A., Giordano, R., Fuentes, S., \& Consolini, L. (2012). ¿Celos, amor, culpa o patología? Cómo perciben la violencia de género en sus relaciones de pareja los/as estudiantes de Trabajo Social. In Actas del $2^{\circ}$ Congreso Interdisciplinario sobre Género y Sociedad:"Lo personal es político" (Vol. 1, No. 1). Recuperado de:

https://www.semanticscholar.org/paper/\%C2\%
BFCELOS\%2C-AMOR\%2C-
CULPA-O-PATOLOG\%C3\%
8DA-C\%C3\%93MO-PERCIBEN-LA-DE-
Soldevila-
Dom\%C3\%ADnguez/
d2295096a44914239b4b6809bd7b7384c
09a48a2? sort=
relevance\&pdf=true $\mathrm{d}=\mathrm{y}$

Soriano-Ayala, E., González-Jiménez, A., \& Soriano-Ferrer, M. (2014). Educación para la salud sexual. Del enamoramiento al aborto. Un estudio cualitativo con adolescentes españoles e inmigrantes. Perfiles Educativos, 36(144). https://doi.org/10.22201/ iisue. 24486167 e.2014.144.46016

Torres, J. Cepero, M. Torres, B. (2010) Relación entre la insatisfacción con la imagen corporal, autoestima, autoconcepto físico y la composición corporal en el alumnado de primer ciclo de educación secundaria de la ciudad de Jaén. Programa de doctorado: Actividad física para la educación en la sociedad del conocimiento. Recuperado de: https://hera.ugr. es/tesisugr/18947761.pdf

Trujillo, E. V., \& Barrera, F. (2002). ADOLESCENCIA, RELACIONES ROMÁNTICAS Y ACTIVIDAD SEXUAL: UNA REVISIÓN. Revista Colombiana de Psicología, 115-134. Recuperado de: https://www.redalyc. org/pdf/804/80401109.pdf

Vivanco, Ramón; Espinoza, Soraya; Romo, Cristian; Véliz, Alex y Vargas, Antonio (2015). Perpetración y victimización de la violencia en relaciones de pareja en jóvenes que cursan educación superior en la ciudad de Osorno, Chile. Polis, pp. 2-14. Santiago: CISPO. http://e-spacio.uned.es/fez/view/ bibliuned:revistaComunitania-2017-13-7020 